\title{
Article \\ Sources of Onboard Fumes and Smoke Reported by U.S. Airlines
}

\author{
Judith Anderson (1)
}

check for updates

Citation: Anderson, J. Sources of Onboard Fumes and Smoke Reported by U.S. Airlines. Aerospace 2021, 8, 122. https://doi.org/10.3390/ aerospace 8050122

Academic Editor: Dieter Scholz

Received: 1 March 2021

Accepted: 17 April 2021

Published: 22 April 2021

Publisher's Note: MDPI stays neutral with regard to jurisdictional claims in published maps and institutional affiliations.

Copyright: (c) 2021 by the author. Licensee MDPI, Basel, Switzerland. This article is an open access article distributed under the terms and conditions of the Creative Commons Attribution (CC BY) license (https:/ / creativecommons.org/licenses/by/ $4.0 /)$.
Department of Air Safety, Health, \& Security, Association of Flight Attendants-CWA AFL-CIO, 501 3rd St. N.W. Washington, DC 20001, USA; judith@afanet.org

\begin{abstract}
This paper describes the relative frequency of reports of oil and hydraulic fluid fumes in the ventilation supply air ("fume events") compared to other types of fumes and smoke reported by U.S. airlines over 10 years. The author reviewed and categorized 12,417 fume/smoke reports submitted to the aviation regulator to comply with the primary maintenance reporting regulation (14 CFR § 121.703) from 2002-2011. The most commonly documented category of onboard fumes/smoke was electrical (37\%). Combining the categories of "bleed-sourced", "oil", and "hydraulic fluid" created the second most prevalent category (26\%). The remaining sources of onboard fumes/smoke are also reported. To put the data in context, the fume event reporting regulations are described, along with examples of ways in which certain events are underreported. These data were reported by U.S. airlines, but aviation regulations are harmonized globally, so the data likely also reflect onboard sources of fumes and smoke reported in other countries with equivalent aviation systems. The data provide insight into the relative frequency of the types of reported fumes and smoke on aircraft, which should drive design, operational, and maintenance actions to mitigate onboard exposure. The data also provide insight into how to improve current fume event reporting rules.
\end{abstract}

Keywords: aircraft; fume event; reporting; engine oil; hydraulic fluid; electrical

\section{Introduction}

The majority of commercial and military aircraft are designed to extract (or "bleed") the cabin and flight deck ventilation air from an engine compressor located upstream of the cabin and flight deck, whether the compressor is in the main aircraft engines or an auxiliary engine in the tail of the aircraft called the auxiliary power unit (APU). The problem with this "bleed air" design is that the oil that lubricates the engine compressors can contaminate the ventilation supply air. This can be caused by an actual mechanical failure or by the effects of engine parts subjected to physical and thermal stress during engine power setting changes, improper oil drainage/reingestion, or overfilling of an oil reservoir during servicing [1-4]. Additionally, small amounts of oil seep past the engine/APU bearing chamber seals into the compressor air flow, which is considered normal and acceptable if the volume of oil loss over time is within defined limits [1-4]. When oil contaminates the bleed air stream, the fumes are delivered to the cabin and flight deck located downstream of the compressor. The APU (and, less often, the main engines) can also ingest hydraulic fluid that has spilled or leaked from a burst line, a worn part, or overfilling during servicing. The ingested hydraulic fluid is also heated in a compressor and, likewise, contaminates the ventilation air supplied to the flight deck and cabin. Engine oil and hydraulic fluid fumes contain a complex mixture of compounds, including base stocks, additives, and decomposition products generated upon exposure to heat and moisture [1,5]. Because current systems are not equipped with bleed air filters, these contaminants are mixed with the ventilation air and delivered to the occupied zones through the cabin and flight deck air supply vents.

Of the compounds that can contaminate the aircraft air supply system, oil and hydraulic fluid have received the most attention because of decades of reports of compromised flight safety and security when crewmembers are either impaired or incapacitated by acute 
symptoms inflight [6-9]. Additionally, these "fume events" are associated with operational impacts, such as diversions, cancellations, and repeat events $[10,11]$, as well as reports of chronic neurological and respiratory illness [12,13].

However, there are other sources of supply air contamination onboard aircraft, including engine exhaust, deicing fluid, birds, engine wash, and ambient pollution. Additionally, there are sources of airborne chemical contaminants inside the cabin and flight deck, including electrical systems (e.g., lights, heaters, doors, and entertainment systems), fans (e.g., ventilation recirculation, cooling blowers, etc.), ducting (blown or clogged), and defective batteries.

Globally, within the aviation industry, there is discussion and debate over the relative frequency and nature of the different types of onboard fumes/smoke reported by crewmembers to airlines and by airlines to regulatory agencies. The answers to these questions of "how often" and "what type" of onboard fumes are important because they directly influence the debate regarding what design, operational, and maintenance regulations are needed (if any) to mitigate exposure to fumes. Some reports recommend engineering control measures and worker training programs to prevent onboard exposure to engine oil and hydraulic fluid fumes to mitigate the associated flight safety and crew health hazards [14-16]. Other reports downplay the frequency and seriousness of engine oil and hydraulic fluid fume events, acknowledging that they occur, but referring to them as "smell events" and claiming that they are either "rare" or "extremely rare" [17-20], rendering additional engineering and maintenance control measures unnecessary.

The aviation regulator in the United States (Federal Aviation Administration, FAA) has acknowledged that airlines underreport fume events [21] and that some of the fume event data that airlines submit is not reported properly [22]. However, even the number of events that airlines document with the FAA significantly underrepresents the actual number of events because airlines are not required to report either events that occur during ground operations or events for which fumes or smoke were present, but a mechanical fault was not subsequently identified. Further, the FAA has significantly undercounted the number of oil and hydraulic fume event reports it received from U.S. airlines [23].

To identify the most effective means to mitigate exposure to onboard fumes and smoke, it is helpful to start by assessing the relative frequency of the sources of onboard fumes and smoke that are documented.

\section{Materials and Methods}

On 14 March 2014, the author filed a Freedom of Information Act (FOIA) request with the FAA, formally asking for a copy of reports of fumes and smoke in the cabin/flight deck that the FAA received from U.S. airlines occurring from 1 January 2002 through 31 December 2011 and including one or more of the following search terms: fume, odor, smell, smoke, bleed air. On 19 May 2015, the FAA sent the author two spreadsheets, one of which contained 15,885 reports that met the author's criteria and had been reported by airlines to comply with the agency's Service Difficulty Reporting (SDR) regulation (14 CFR $\S 121.703)$. The other spreadsheet contained 366 reports that also met the author's criteria and had been reported by airlines to comply with the agency's Accident and Incident Data System (AIDS) rule (Order 8020.11D, 2018). Other than a cursory review of the narrative fields, the AIDS data are not summarized in this study.

For each SDR fume/smoke report, the author reviewed the narrative field ("remarks") and other relevant details to determine the source of the fumes or smoke. The author excluded reports that did not involve actual fumes or smoke in the cabin or flight deck, and then categorized the remaining reports according to the specified/implied source of fumes (Table 1), based on a combination of the text in the narrative field and professional judgement. The categories were applied consistently throughout the data set according to objective criteria, wherever possible. For some reports, selecting the category involved a degree of personal judgement, for example, fumes from a failed or defective fan were generally classified as "fan", even though some of the failures were electrical rather than 
mechanical. For narratives that described an unfamiliar mechanical condition or fault, the author relied on the professional judgement of two senior airline mechanics and two commercial airline pilots, respectively.

Table 1. Types/sources of onboard fumes/smoke.

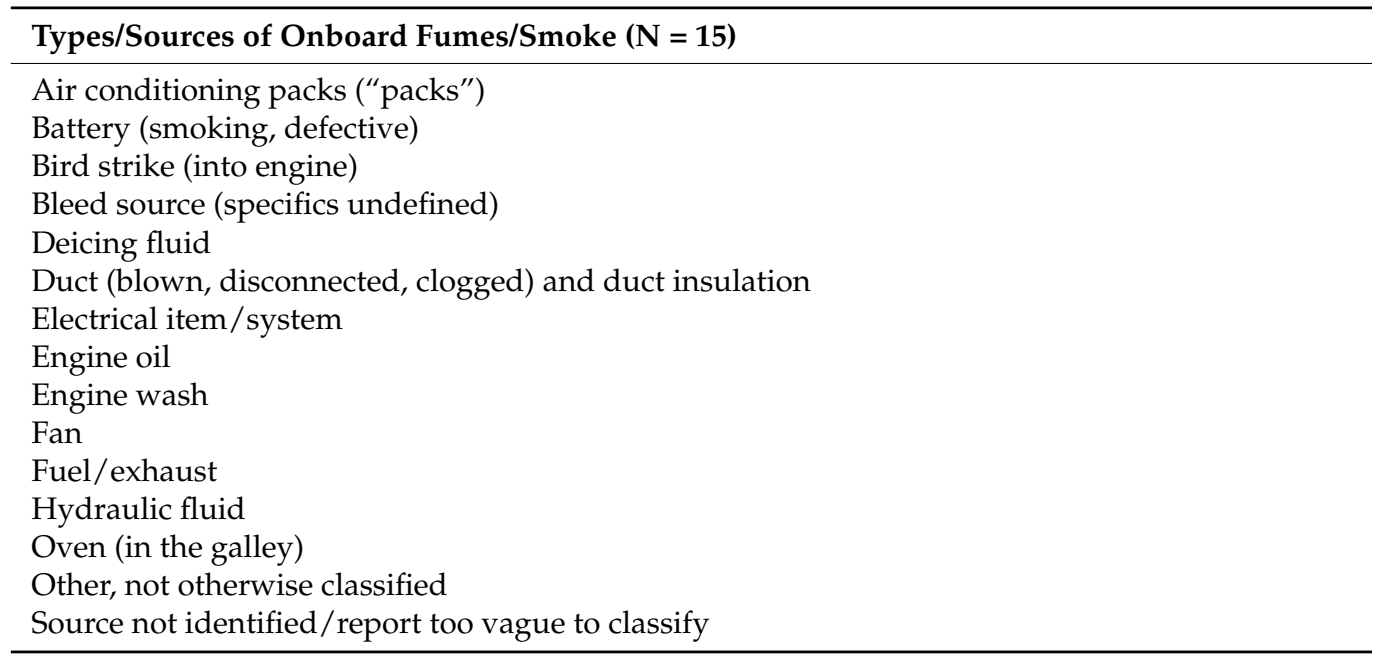

When airline staff submit a fume/smoke report to the FAA's SDR system, they cite the "maintenance manual" chapter assigned to the report internally. These chapters were created by the Air Transport Association (ATA) and define both how airline pilots classify abnormal conditions in their logbooks, and how maintenance workers classify aircraft system troubleshooting and repairs in the maintenance records, all of which are traceable to the aircraft tail number. As another source of insight into sources of documented fumes and smoke inflight, the author summarized the airline-defined ATA chapters for the whole data set and for the three leading sources of fumes.

\section{Results}

Of the 15,885 reports, the author excluded 3468 reports that did not involve an actual smoke or fume in the cabin or flight deck. Examples include "lens of smoke goggle was cracked" or "test of smoke detector failed". Those narratives included the word "smoke", but it is clear that no smoke was present.

\subsection{Types of Onboard Fumes/Smoke Reported by U.S. Airlines}

A total of 12,417 reports remained, including 12,382 reports that were assigned to one source category based on the narrative description, and 35 reports that were assigned to two categories, creating a total of 12,452 source types (Figure 1). Electrical fumes were the most documented type of report (37\%). The combination of "bleed-sourced", "engine oil", and "hydraulic fluid" represented the second most documented type of report (26\%). The third most documented mechanical failure that generated smoke or fumes was fans $(8.5 \%)$, followed by air conditioning packs (6.4\%), and fuel/exhaust (5.2\%). A total of $1.8 \%$ of the reports were "other, not otherwise classified", which included sources that did not fit the other categories, such as engine failures, blown tires, and lightning strikes. Notably, for $9.1 \%$ of the reports, either the mechanical fault that created the fumes/smoke was either not identified or the airline supplied insufficient information for the author to reliably classify the source (e.g., "fumes reported during climb in the aft cabin"). 


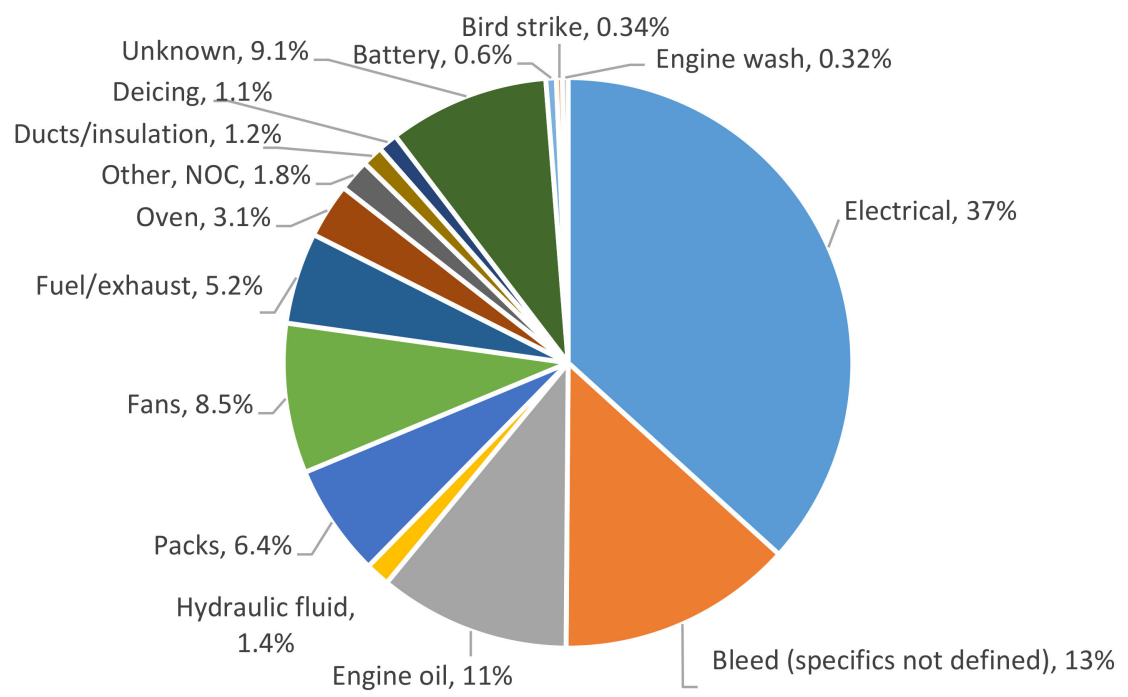

Figure 1. Sources of onboard fumes/smoke reported by U.S. airlines, 2002-2011 ( $n=12,452)$.

\subsection{ATA Chapters, Whole Dataset}

Airlines classified $89 \%$ of the 12,417 reports into the nine ATA chapters listed in Figure 2, led by air conditioning (45\%), and followed by lights (9.1\%), equipment/furnishings $(8.5 \%)$, airborne APU (8.1\%), and engine (6.1\%). The "other" category (Figure 2) represents reports that airlines classified into 29 additional ATA chapters, ranging from one to 211 reports per chapter.

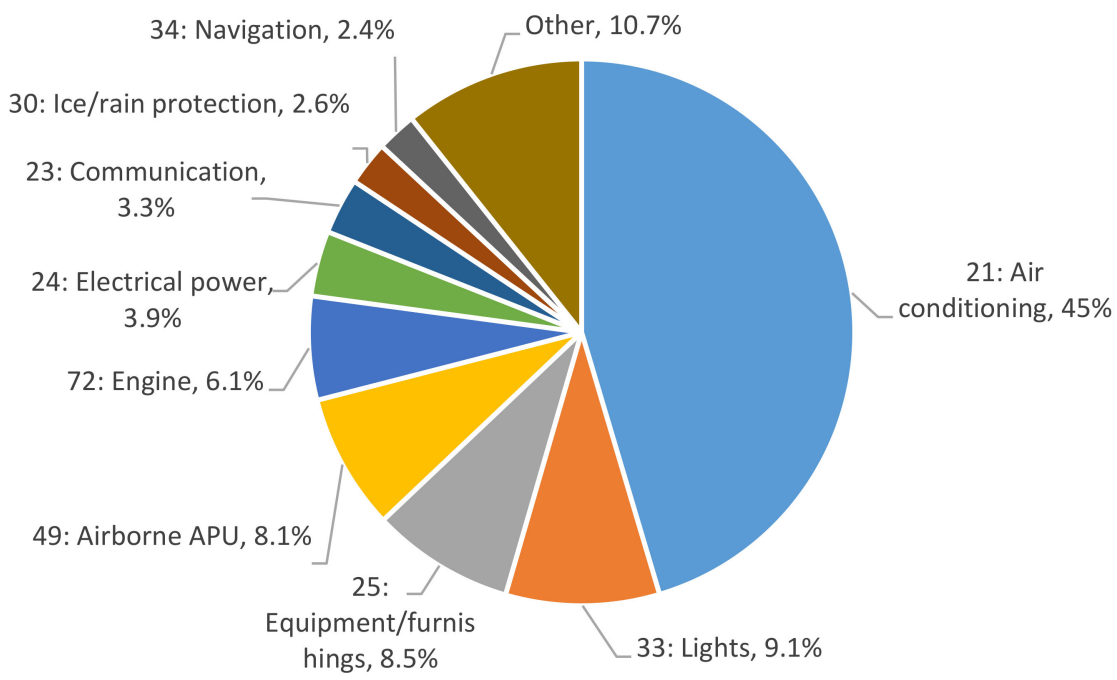

Figure 2. ATA chapters assigned by airlines to fumes/smoke reports, 2002-2011 ( $n=12,417)$.

\subsection{ATA Chapters, Onboard Electrical Fumes/Smoke}

Of the 4573 reports that the author classified as electrical, the most commonly cited ATA chapters were lights (24\%), air conditioning (15\%), and equipment/furnishings (13\%). The nine ATA chapters for $89.2 \%$ of these electrical reports are listed in Figure 3. Airlines classified the remaining $10.8 \%$ of the electrical reports into one of 24 additional ATA chapters (listed as "other" in Figure 3), reflecting the number and diversity of electrical systems onboard. 


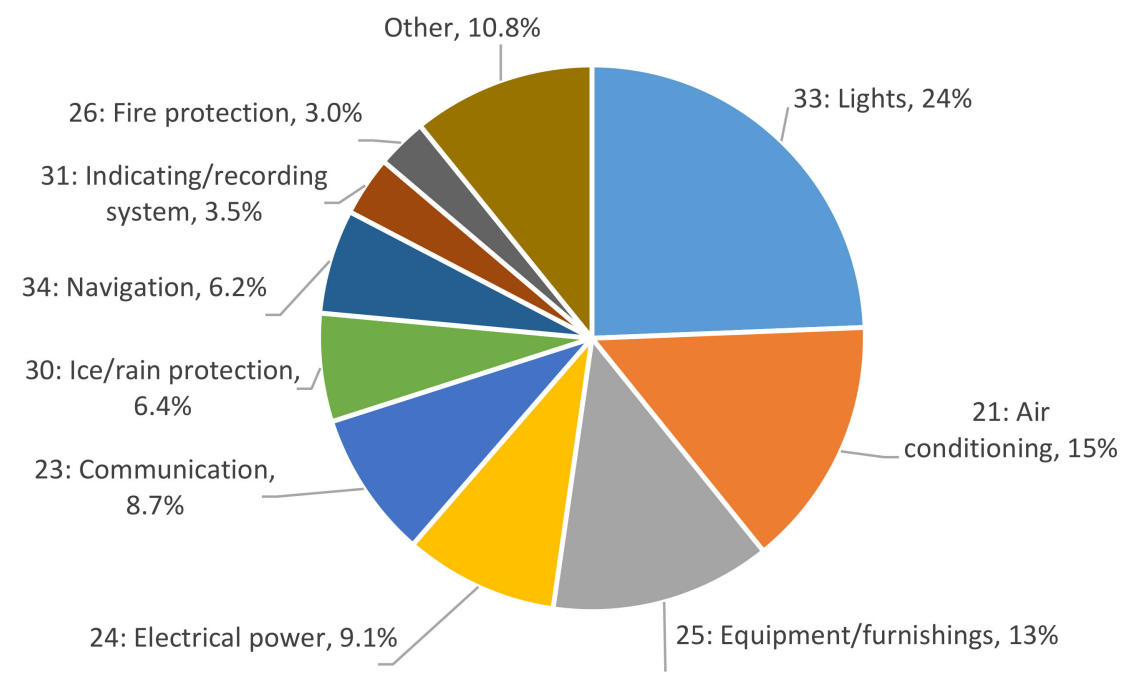

Figure 3. ATA chapters assigned by airlines to 4573 reports of electrical fumes/smoke.

\subsection{ATA Chapters, Onboard Fume Events (Engine Oil, Hydraulic Fluid)}

Of the 3360 reports that the author classified as either engine oil, bleed-sourced, or hydraulic fluid, the most commonly cited ATA chapters were air conditioning (51\%), engine (20\%), APU (18\%), hydraulic power (3.7\%), pneumatic (1.6\%), and bleed air (1.1\%) (Figure 4). Airlines classified the remaining 3.9\% of these reports in one of 20 additional ATA chapters (listed as "other" in Figure 4). Note that four of the 3360 fume reports were classified as both oil and hydraulic fluid because maintenance found both contaminants in the bleed system during troubleshooting, but each of those four reports only had one assigned ATA chapter.

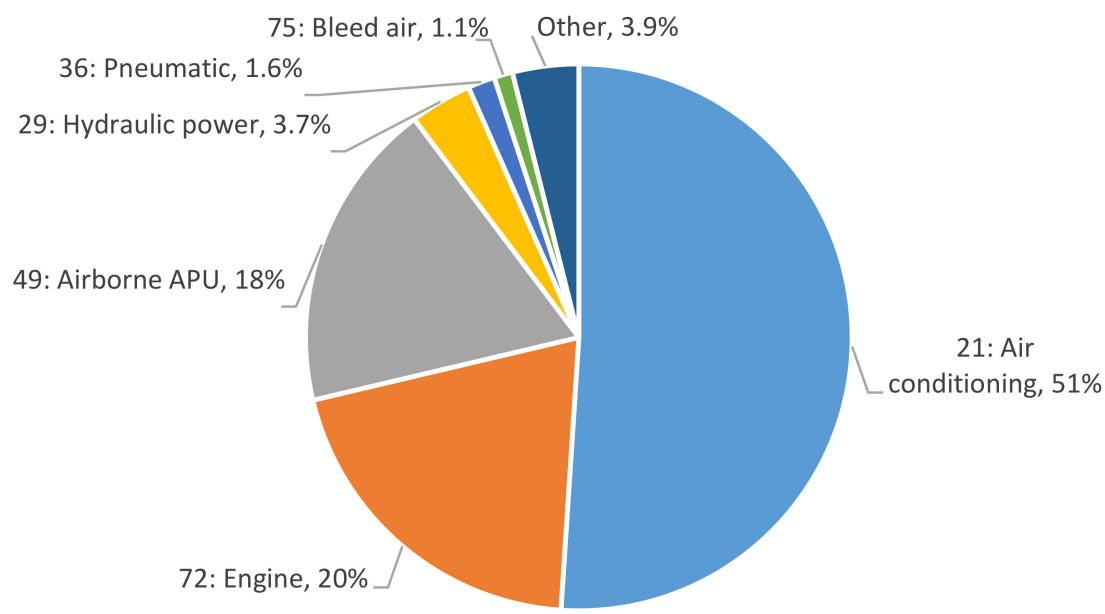

Figure 4. ATA chapters assigned by airlines to 3360 fume events (oil, hydraulic, bleed).

\subsection{ATA Chapters, Onboard Fan-Sourced Fumes, and Smoke}

Failures or malfunctions in a total of 23 types of fans were referenced in the fume and smoke reports (Table 2), eight of which appear to be related to the air conditioning system and are indicated with bold text in Table 2. Of the 1058 reports that the author classified as "fans", airlines classified the vast majority (96\%) as air conditioning (ATA chapter 21). Airlines classified the remaining $4 \%$ of fan failures into one of 11 ATA maintenance manual chapters. 
Table 2. Types of fans referenced in fume/smoke reports.

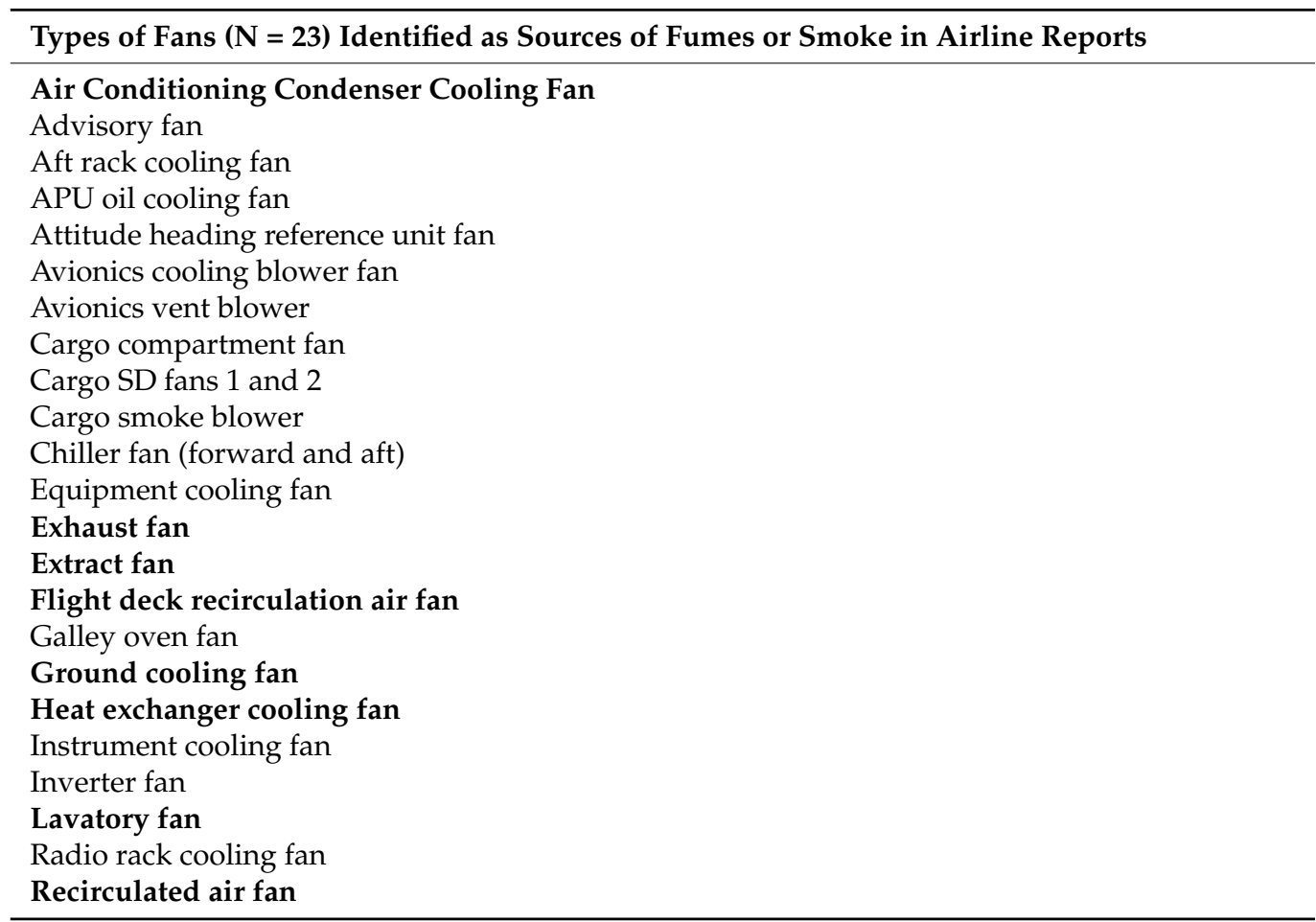

\subsection{Other Sources of Onboard Fumes/Smoke}

In all, $6.4 \%$ of the 12,452 source types for the 12,417 reports $(n=793)$ were classified as "air conditioning packs" (indicated as "packs" in Figure 1) and 13\% $(n=1667)$ were classified as "bleed, specifics not defined". There is more judgement involved with these categories than the others because, generally, the pack itself is not as much a source of contamination as it is a sink for sources of upstream contaminants. Those contaminants can be internal (e.g., leaking oil seal in the engine) or external (e.g., ingested exhaust fumes) and the soiling may build up gradually or be associated with a specific upstream failure. Additionally, the pack contains electrical components, which can fail. For these types of air supply system-sourced fumes, the author and, often, one of the selected experts (two pilots and two senior mechanics) had to make a judgement call as to whether the fumes were more likely sourced to the pack, bleed air upstream of the pack, or another external source. Generally, the "packs" category was chosen if a mechanical fault was later found in the pack. Such mechanical faults were typically not specified but were suggested because all or part of the pack was replaced. Conversely, the "bleed, specifics not defined" category was chosen if the fumes were reported during an engine power setting change (usually take-off/climb or descent), no mechanical fault was subsequently found (or inferred) in the pack, and an external source (such as exhaust fumes) was not referenced. A small subset of pack failures were classified as "engine oil" if the description of fumes was consistent with oil and the air cycle machine bearings in the pack would have been oil-lubricated.

In all, $1.8 \%$ of the 12,452 source types $(n=224)$ were classified as "other, not otherwise classified". The sources in this category included engine failures (unless oil fumes were specified), supply air from a ground cart, lightning strikes, blown tires, lavatory fluid, and maintenance products, such as grease or solvents.

Only 10 of the 12,417 fume/smoke reports cited odors that were sourced to either lavatory fluid or waste (e.g., servicing issue, blocked drain, leaking lav seals), so these were not assigned an independent category. Additionally, despite anecdotal reports that nail polish is a significant source of onboard fumes, there were only six reports that mentioned the smell of either nail polish or acetone, and the maintenance response indicated that none 
of those reports were sourced to either product. Presumably, lavatory odors and nail polish are easily identifiable and, generally, do not require maintenance intervention.

\section{Discussion}

\subsection{Airline Reporting Rules for Onboard Fumes/Smoke}

In the U.S., commercial airlines are required to report each "failure, malfunction, or defect" that causes "smoke, vapor, toxic or noxious fumes" to accumulate or circulate in the flight deck or cabin during flight (defined as "wheels up") (14 CFR § 121.703(a)(5)). Airlines are also required to report ground-based events if the airline is of the "opinion" that flight safety could have been "endangered" had the aircraft continued (14 CFR § 121.703(c)). There are comparable SDR rules for charter flights, too (14 CFR § 135.415). These "Service Difficulty Reporting" (SDR) rules will not capture fume events for which the causal defect is not apparent during a ground-based inspection. For example, oil fumes that contaminate the bleed air through a worn engine part subjected to thermal or physical stress during an engine power setting change inflight need not be reported if that same part does not leak under ground-based conditions during a maintenance inspection. As well, when maintenance workers overfill the oil or hydraulic fluid reservoir, the subsequent spillage into the bleed air is a recognized source of fumes [24-26], but spillage is not a mechanical defect, so does not need to be reported.

In this dataset, $9.1 \%(n=1135)$ of the SDR reports from airlines to the FAA do not offer insight into the relevant mechanical defect or failure. It is not clear if the fault is not described or not known when the report is submitted. Technically, though, it is the defect that is reportable, not the presence of fumes. Even though, there may not be an actual defect and, even when there is, maintenance troubleshooting can be "trial and error" [27], which can delay defect identification.

In addition to the SDR regulation for reporting onboard fumes and smoke, U.S. airlines must also report each "interruption to a scheduled flight" caused by a known or suspected (emphasis added) mechanical difficulty or malfunction, which is not required to be reported under the SDR rule (14 CFR § 121.705). However, it is difficult to assess the degree to which airlines comply with this rule because there is no central, searchable FAA database; rather, these "mechanical interruption reports" are maintained by individual FAA Certificate Management Offices, and only for one year.

Finally, U.S. airlines must also report "occurrences which affect or could affect safety of operations", including onboard fumes/smoke, to the FAA's "Accident and Incident Data System" (AIDS) per Order 8020.11D (2018). The author's 2014 FOIA request included AIDS reports with one or more of the same search terms requested for the SDR data, but U.S. airlines only submitted $2.3 \%$ as many fume/smoke reports to meet Order $8020.11 \mathrm{D}$ as compared to the SDR regulation ( $n=366$ compared to 15,885$)$ during the same time period. It would be reasonable to assume that AIDS reports are the more serious events during which safety of operations was (or could have been) compromised. To test this hypothesis, the author compared the contents in the narrative fields of the AIDS and SDR datasets (which were selected based on the same set of search terms during the same time frame) and concluded that the nature and seriousness of the reports is comparable. It appears that the AIDS regulation is either ignored or misunderstood, and that compliance is not enforced.

In summary, then, if airline staff do not identify a mechanical source of reported fumes, or if the fumes occur before take-off, then the event is not reportable. If airline staff do identify a mechanical source of fumes, then the airline must report to the SDR database. If a mechanical source was suspected and the flight plan was affected, then the airline must report to the "mechanical interruption" database. In both of those scenarios, if safety either was or could have been compromised, then the airline must also report to the AIDS system. However, ground-based fume events can still compromise safety, fumes can occur without obvious mechanical defects, and an airline is unlikely to report the same event to two reporting systems. As a result, these reports of fumes and smoke are only a subset of the 
actual events, and the data that do exist get scattered, all making an accurate assessment of the relative and absolute frequencies of different sources of onboard fumes and smoke even more difficult.

In addition to the complying with FAA reporting rules, U.S. airlines must report fume and smoke events to the U.S. National Transportation Safety Board (NTSB), if the event meets the NTSB definition of either an "accident" or "serious incident" (49 CFR § 830.5, 49 CFR $\S 830.2$ ). Some fume events meet the NTSB reporting criteria, such as when a crewmember is hospitalized for more than $48 \mathrm{~h}$ during the seven days post-flight, sustains internal organ damage, or is unable to perform normal flight duties.

Another source of fume event data for the U.S. fleet is the "Aviation Safety Reporting System" (ASRS) database, hosted by the National Aeronautics and Space Administration (NASA). ASRS catalogues aircraft incident reports for a broad range of unsafe conditions from pilots, cabin crew, maintenance workers, air traffic controllers, and dispatchers. Reporting is voluntary and confidential, with the goal of circulating information about safety issues within the industry to prevent reoccurrences. Of 341 ASRS "smoke/fire/fumes/odor" events that crewmembers reported in 2016-2017, 35\% were sourced to the air supply system and $20 \%$ were sourced to electrical faults [28].

\subsection{Underreporting Engine Oil and Hydraulic Fume Events}

Unfortunately, even within the narrowed scope of the reporting rules for fume and smoke events, there is evidence of airline underreporting. Some of the underreporting is cited for fume events in general. For example, in 2006, the FAA issued a bulletin for its maintenance inspectors, acknowledging poor airline compliance with the fume event reporting regulations. Specifically, the agency noted that "there have been concerns raised about numerous reports of [fume] events on commercial air carrier/operator aircraft. During the FAA's analysis of this [sic] data, it appears as though there are numerous [airlines] who may not have reported these events as required by regulation" [21].

There is evidence, however, that some underreporting is specific to oil and hydraulic fume events, reducing both the number of reports and the relative frequency of those events. For example, a review of fume events consistent with oil and hydraulic fluid sources at one U.S. airline over 18 months in 2009-2010 found that the airline had only reported $38 \%$ of 87 fume events documented by crewmembers to the FAA SDR system [11]. Part of this discrepancy is explained by the airline not consistently complying with the reporting rules, but part of it is explained by regulatory language that does not require airlines to report a significant fraction of documented events, as described above.

An example of underreporting specific to engine oil fumes is a 2013 report that the FAA sent to two Congressional committees regarding a law requiring the FAA to conduct research and development into sensor and filtration technology, specific to preventing exposure to oil fumes in the bleed air on commercial aircraft [29]. The FAA reported to Congress that officials had "mined" their fume event databases from 2002-2011, inclusive, for reports that included one or more of the search terms "fume, odor, smell, smoke, and bleed air", and that U.S. airlines had only reported 69 oil fume events and no hydraulic fluid events during those 10 years [23]. The FAA told Congress that, since the occurrence of these events was "extremely low", it could not justify spending its resources to research and develop bleed air sensors and filters. However, this analysis of those same cited reports from just one of the FAA databases using the same search terms identified oil as a source of fumes in 1353 reports, hydraulic fluid as a source in 173 reports, and bleed air contaminants consistent with oil/hydraulic fluid in 1667 reports. This type of underreporting reduces the relative frequency of these reports and downplays the need for relevant regulatory control measures.

Finally, underreporting oil and hydraulic fluid fume events is not limited to U.S. airlines. In 2011, the European Aviation Safety Agency (EASA) published comments it had received in response to the question of whether a rulemaking to address oil fumes in the cabin and flight would be justified. EASA noted multiple claims by advocates for pilots, 
cabin crew, and passengers that European airlines underreport (a word used 53 times in the report) fume events and that the safety impacts are downplayed [30]. Likewise, a report by the Australian Transport Safety Bureau (ATSB) noted evidence that Australian airlines underreport fume events, both to the ATSB and to the aviation regulator [31]. An Australian Senate Enquiry into fume events on one particularly problematic aircraft type noted "strong evidence of a tendency of pilots to under-report [fume events]", citing a combination of pressure from airline management and lack of training [32]. The International Civil Aviation Organization (ICAO) has formally recommended that airlines "encourage flight and cabin crew members to report fume events", referring to crew reports as "essential to assist airline maintenance technicians in identifying the root cause of an event and taking corrective action to prevent reoccurrence" [14]. Currently, though, fume event reporting to aviation regulators is largely limited to maintenance defect reporting.

\subsection{Estimates of the Frequency of Engine Oil and Hydraulic Events}

The answer to the question of how often oil and hydraulic fluid fume events happen during commercial airline flights is a subject of considerable debate within the industry. It is important to get an accurate answer because, as the FAA's 2013 report to Congress illustrates [23], the answer will influence the regulatory agenda. The FAA itself acknowledges this reality in a 2016 bulletin in which the agency notified airlines "that some data required by [the SDR rule] is not being entered properly" and that "[b]ecause of poor data integrity, the FAA, manufacturers, and air carriers are unable to accurately detect trends necessary to proactively mitigate risk" [22].

One of the first estimates of how often oil and hydraulic fluid fume events occur was published in a 2002 U.S. National Research Council (NRC) committee report about aspects of aircraft air quality associated with potentially negative impacts on crew and passenger health. The report referenced fume event data collected at three airlines "over several years", which ranged from 0.9 events per 10,000 flights on Boeing 737 aircraft up to 39 events per 10,000 flights for the British Aerospace 146 [33]. The NRC committee issued a series of recommendations to the FAA, including that the agency "rigorously demonstrate" the "adequacy" of its cabin air regulations. In response, the FAA acknowledged that its "rulemaking has not kept pace with public expectation and concern about air quality and ... [n]o present airplane design ... incorporates an air contaminant monitoring system to ensure that the air provided to the occupants is free of hazardous contaminants ... " [34]. As of this writing, the FAA has still not initiated a rulemaking on this subject.

In 2010, the FAA published an informational bulletin for airlines, stating that the agency " . . continues to receive over 900 reports a year on [all sources of] smoke or fumes in the cabin and or cockpit" [35]. Based on the number of flights in 2010 [36], this translates into 0.9 events per 10,000 flights. The FAA noted that, "in fact, it is not unusual to receive more than one report during a 24-h period. For instance, on one day in April of 2010, five reports of smoke in the cockpit came in from one [airline]. All these incidents prompted the flightcrew to declare emergencies and divert to the nearest airport" [35].

In 2013, the International Air Transport Association (IATA) reported on its analysis of operational safety reports from more than 150 airlines covering almost 31 million flights during the period 2008-2012 [37]. Of these, 3444 reports were categorized as "smoke, fumes, and odor", which is equivalent to about one reported event per 10,000 flight cycles. Engine-related fumes were the most commonly reported source (23\%), followed by electrical-related fumes (15\%). Maintenance action was the most common operational effect (25\%).

In 2015, FAA-funded researchers published their review of engine oil and hydraulic fluid fume events identified in FAA, NTSB, and NASA databases from 2007-2012 and sorted them by aircraft type. They concluded that U.S. airlines reported fume events on almost every aircraft type at an average frequency of two events per 10,000 flights [38], which translates into an average of 5.3 events per day based on the number of flights operated 
during that time [36]. The authors reported "substantial variation" in the frequency of reports by aircraft type, with the maximum being eight reported events per 10,000 flights.

\subsection{Recommendations to Improve Data Collection for Onboard Fumes/Smoke}

Beyond the need for better compliance and enforcement of existing regulations, this review of SDR data from 2002-2011 provides insight into how fume reporting regulations could be improved.

First, SDR data would be more representative if airlines were required to report the presence of onboard fumes/smoke during ground operations, not just inflight. Industry sources confirm that the APU (which is the typical bleed air source during ground operations, whether at or away from the gate) is a source of oil and hydraulic fluid fumes [25]. Reports confirm that APU oil fumes, which contaminate the cabin or flight deck air during ground operations, can generate reports of crew ill health [11]. Additionally, if fumes that manifest on the ground are not resolved, they can continue inflight [25], which can affect both the safety of operations [26] and the health of the crew and passengers [11]. For these reasons, ground-based fume events should be documented and prevented.

Second, reported onboard fumes/smoke for which there is no obvious mechanical fault should still be reportable. For example, overfilling an oil or hydraulic fluid reservoir is a recognized source of fumes [26,39]. Additionally, some faults (such as oil leakage through a worn but not defective engine seal) that introduce fumes to the cabin air may only happen during the stress of a high-engine power setting, for example, and may not be recreated during routine ground-based troubleshooting [40]. Maintenance staff may not identify the relevant mechanical failure even for serious events, such as those involving pilot impairment and incapacitation [6]. SDR data would be more representative and useful if the presence of fumes/smoke caused by even a suspected defect or failure (defined to include spills and leaks) was reportable.

Third, it would be easier for SDR database users to answer the "how often" and "what type" questions regarding onboard fumes/smoke if the FAA's report categories were more tailored to the actual sources of fumes (see Figure 1), or if airlines could choose more than one category. For example, a pull-down menu for airlines to select standardized responses to the question of "source" would assist with subsequent analyses. The narrative field for each report can provide useful details but is too technical to be interpreted by software. Currently, when an airline submits a report, they must choose the most relevant category ("nature condition"), as defined by the FAA. One of the FAA categories is "smoke/fumes/odors/sparks", but only $76 \%$ of the 3360 events the author classified as "oil", "hydraulic", or "bleed-sourced" were categorized as such. U.S. airlines categorized another $16 \%$ of those bleed air reports as "fluid loss" and assigned the remaining $8 \%$ to one of 13 additional categories. For the full dataset $(n=12,417$, all sources), airlines classified $84 \%$ of the reports as "smoke/fumes/odor/sparks" and 5.4\% as fluid loss. In both cases, selecting only the "smoke/fumes/odor/sparks" category to search for fume and smoke reports seems reasonable but would underestimate the number of relevant reports.

Lastly, a crewmember reporting system for fume events to supplement the existing maintenance reporting systems is needed and must be accompanied by suitable training programs to ensure that crewmembers know how to recognize and respond to different types of onboard fumes and smoke [14]. This point has been raised since at least 2002, starting with an NRC committee, which recommended that the FAA establish a crewmember reporting system to collect air quality event data and associated symptom reports [33]. The following year, Congress passed a law requiring the FAA "to establish an air quality incident reporting system" [41]. Nine years later, Congress again required the FAA to "establish a systematic reporting standard for smoke and fume events in aircraft cabins" [42]. In 2017, the Cabin Air Safety Act of 2017 was introduced to the floor of the U.S. Senate, and the Know Before You Fly Act was introduced to the floor of the U.S. House. Again, these bills called on the FAA to establish a system for crewmembers and mechanics to report fume events on commercial aircraft, but neither bill was passed. In early 2018, the 
FAA recommended that airlines "assess current policy and procedures" regarding their procedures to differentiate and mitigate smoke and fumes, but the FAA did not mandate event reporting [43]. Most recently, in October 2018, Congress mandated that the FAA "issue guidance for airline crews and maintenance technicians to report incidents of smoke or fumes on board an aircraft operated by a commercial air carrier" [44]. In March 2021, the FAA launched a cabin air quality website that includes a link to a voluntary, deidentified reporting system operated by NASA and a link to the FAA's maintenance defect reporting system [45]. However, the FAA has still not implemented crewmember reporting systems for fume events on commercial aircraft.

\section{Conclusions}

Of the onboard fumes/smoke that U.S. airlines reported to the regulatory agency over a 10-year period, electrical-sourced fumes and smoke were the most prevalent (37\%), reflecting the number and diversity of onboard electrical systems and associated faults (Figures 1 and 3).

Bleed air issues (i.e., either confirmed or suspected engine oil and hydraulic fluid fumes) were the second most prevalent type of reported fumes/smoke (26\%), and airlines internally classified $89 \%$ of those reports as either air conditioning, engine, or APU (Figures 1 and 4). Oil fumes were reported almost eight times more frequently than hydraulic fluid fumes (Figure 1).

Fans were the third most prevalent source of reported fumes/smoke (8.5\%), most of them related to the air conditioning systems (Figure 1, Table 2). It would be worth investigating how to either improve the design of these fans or to implement an inspection program (e.g., measure vibration or electrical current draw) as preventive maintenance.

It is important to note that, although these data were reported by U.S. airlines, the harmonized nature of regulations that govern aircraft design, maintenance, and operating practices means that the data likely also reflect the onboard sources of fumes and smoke reported in other countries with equivalent aviation systems.

To more accurately count the number and types of fumes/smoke on U.S.-registered aircraft, it would be helpful if the FAA improved its current maintenance reporting regulations by requiring airlines to report both ground-based events and those for which a mechanical fault is not readily identified. In addition, there is a need for the FAA—and its equivalent regulatory bodies around the world— to implement a reporting system for crewmembers to gather data on the health and safety implications of exposure to air supply system-sourced fumes onboard, as per the recommendation of the ICAO [14].

Finally, the proportion of reported fume events that involve engine oil/hydraulic fluid described here, in conjunction with a more expansive review of the frequency of reported fume events on US airlines [38] and reports that flight safety can be compromised (cited above) support the installation and operation of equipment to filter and monitor bleed air contaminants in real time when aircraft are in operation. In the U.S., research into suitable technologies was most recently called for in legislation passed in 2012 [29] and 2018 [44]. Progress is slow, but there is progress, nonetheless; in late 2020, an FAA-funded research consortium held its first meeting on technologies intended to monitor bleed air contaminants and detect events in real time.

Funding: This research received no external funding.

Institutional Review Board Statement: Not applicable.

Informed Consent Statement: Not applicable.

Data Availability Statement: The database of 12,417 fume/smoke reports (including fields added by the author, distinguished from the FAA fields by red font in the column header), and the associated analyses of fume/smoke sources and ATA chapters can be accessed here: Anderson, Judith, 2021, "Sources of onboard fumes and smoke reported by U.S. airlines", https:/ / doi.org/10.7910/DVN/ FIAUGW, Harvard Dataverse, V1, UNF:6:wIDuQaohfGCvQfNtzPfKCA==[fileUNF] (accessed on 15 April 2021). 
Acknowledgments: The author particularly thanks the two commercial pilots and two airline mechanics for their insights into the sources of fumes and smoke in so many of the reports described in this paper, and also for their patience and good humor.

Conflicts of Interest: The author declares no conflict of interest.

\begin{tabular}{|c|c|}
\hline \\
\hline \multicolumn{2}{|c|}{ Abbreviations } \\
\hline APU & Auxiliary Power Unit \\
\hline ASRS & Aviation Safety Reporting System \\
\hline ATA & Air Transport Association \\
\hline ATSB & Australian Transport Safety Bureau \\
\hline FAA & United States Federal Aviation Administration \\
\hline NASA & United States National Aeronautics and Space Administration \\
\hline NRC & United States National Research Council \\
\hline NTSB & United States National Transportation Safety Board \\
\hline SDR & Service Difficulty Report \\
\hline
\end{tabular}

\section{References}

1. Johnson, D.W. Turbine engine lubricant and additive degradation mechanisms. In Aerospace Engineering; Intech Open: London, UK, 2018; p. 19. Available online: https://doi.org/10.5772/intechopen.82398 (accessed on 12 April 2021).

2. USPTO. Seal Assembly and Method for Reducing Aircraft Engine Oil Leakage; U.S. Patent No. 10927845; assigned to The Boeing Company; Lin, C.-H., Horstman, R., Bates, G., Eds.; US Patent \& Trademark Office: Washington, DC, USA, 2021. Available online: https:/ / perma.cc/8D7V-Q863 (accessed on 9 April 2021).

3. Michaelis, S. Aircraft clean air requirements using bleed air systems. Engineering 2018, 10, 142-172. Available online: https: / / doi.org/10.4236/eng.2018.104011 (accessed on 14 April 2021). [CrossRef]

4. Chupp, R.E.; Hendricks, R.C.; Lattime, S.B.; Steinetz, B.M. Sealing in Turbomachinery, NASA/TM-2006-214341; National Aeronautics and Space Administration, Glenn Research Center: Cleveland, OH, USA, 2006. Available online: https:/ / perma.cc/PY5C$4 \mathrm{LHU}$ (accessed on 12 April 2021).

5. Van Netten, C.; Leung, V. Hydraulic fluids and jet engine oil: Pyrolysis and aircraft air quality. Arch. Environ. Health 2001, 56, 181-186. Available online: https:/ / doi.org/10.1080/00039890109604071 (accessed on 12 April 2021). [CrossRef] [PubMed]

6. AAIB. Bulletin No. 9/2020, G-EUYB (AAIB-26125), Air Accidents Investigation Branch; UK Department for Transport: Aldershot, UK, 2020. Available online: https:/ / perma.cc/GWD2-RWVW (accessed on 12 April 2021).

7. AAIB. Bulletin No. 3/2013, G-FCLA (EW/G2012/10/09). Air Accidents Investigation Branch; UK Department for Transport: Aldershot, UK, 2013. Available online: https:/ / perma.cc/QE5D-SLDX (accessed on 9 April 2021).

8. Montgomery, M.R.; Wier, G.T.; Zieve, F.J.; Anders, M.W. Human intoxication following inhalation exposure to synthetic jet lubricating oil. Clin. Toxicol. 1977, 114, 423-426. Available online: https:/ / doi.org/10.3109/15563657708988205 (accessed on 12 April 2021). [CrossRef] [PubMed]

9. Armstrong, H.G. Noxious fluids and gases in aviation. In Chapter XI in Principles and Practice of Aviation Medicine; The Williams \& Wilkins Company: Baltimore, MD, USA, 1939; pp. 178-180.

10. AAIB. Bulletin No. 12/2019, G-YMMU (EW/G2019/07/01). Air Accidents Investigation Branch; UK Department for Transport: Aldershot, UK, 2019. Available online: https:/ / perma.cc/JDZ5-CL54 (accessed on 9 April 2021).

11. Murawski, J.T.L. Case study: Analysis of reported contaminated air events at one major U.S. airline in 2009-2010. In Proceedings of the 41st International Conference on Environmental Systems, Portland, Oregon, 17-21 July 2011; American Institute of Aeronautics \& Astronautics: Reston, VA, USA, 2011. Paper ID: AIAA2011-5089. Available online: https://doi.org/10.2514/6.2011-5089 (accessed on 12 April 2021). [CrossRef]

12. Michaelis, S.; Burdon, J.; Howard, C.V. Aerotoxic syndrome: A new occupational disease? Public Health Panor. 2017,3 , 198-211. Available online: https:/ /apps.who.int/iris/handle/10665/325308 (accessed on 12 April 2021).

13. Bobb, A.J.; Still, K.R. Known Harmful Effects of Constituents of Jet Oil Smoke; Report No TOXDET-03-04; Naval Health Research Center Detachment (Toxicology), Wright Patterson Air Force Base: Dayton, OH, USA, 2003. Available online: https://perma.cc/ DNY6-AGZS (accessed on 12 April 2021).

14. ICAO. Circular No. 344-AN/202: Guidelines on Education, Training and Reporting Practices Related to Fume Events; Approved by and published under the authority of the Secretary General; International Civil Aviation Organization: Montreal, QC, Canada, 2015; ISBN 978-92-9249-856-6. Available online: https:/ / perma.cc/R4UZ-DNQH (accessed on 12 April 2021).

15. AAIB. Bulletin No. 4/2007, G-JECE (EW/C2005/08/10). Air Accidents Investigation Branch; UK Department for Transport: Aldershot, UK, 2007. Available online: https:/ / perma.cc/7JX9-8JBC (accessed on 12 April 2021). 
16. Reddall, H.A. Elimination of Engine Bleed Air Contamination. In Proceedings of the SAE Golden Anniversary Aeronautic Meeting, Hotel Statler, Los Angeles, CA, USA, 11-15 October 1955; SAE Technical Paper 550185. SAE Aerospace: Warrendale, PA, USA, 1955. Available online: https:/ / doi.org/10.4271/550185 (accessed on 14 April 2021).

17. Schuchardt, S.; Koch, W.; Rosenberger, W. Cabin air quality-Quantitative comparison of volatile air contaminants at different flight phases during 177 commercial flights. J. Build. Environ. 2019, 48, 498-507. Available online: https://doi.org/10.1016/j. buildenv.2018.11.028 (accessed on 14 April 2021). [CrossRef]

18. EASA. Research Project: CAQ Preliminary Cabin Air Quality Measurement Campaign; Report No. EASA_REP_RESEA_2014_4; Schuchardt, S., Bitsch, A., Koch, W., Rosenberger, W., Eds.; European Aviation Safety Agency: Cologne, Germany, 2017; Available online: https:/ / perma.cc/EN8D-6YY7 (accessed on 9 April 2021).

19. FAA. Bleed Air Contaminants: A review, DOT/FAA/AM-15/20; Day, G.A., Ed.; Civil Aerospace Medical Institute, Federal Aviation Administration: Oklahoma City, OK, USA, 2015. Available online: https:// perma.cc/4SGU-GN9T (accessed on 9 April 2021).

20. Boeing. Memorandum by the Boeing Company, Seattle, Washington. Submitted to: Air Travel and Health: An Update. UK House of Lords Science and Technology Committee, 1st Report of Session 2007-2008, Published by the Authority of the UK House of Lords. The Stationery Office Limited: London, UK, 2007; pp. 113-115. Available online: https://perma.cc/54L7-E5HR (accessed on 9 April 2021).

21. FAA. Flight Standards Information Bulletin for Airworthiness (FSAW) 06-05A: Guidance for Smoke/Fumes in the Cockpit/Cabin. U.S. Federal Aviation Administration: Washington, DC, USA, 2006. Available online: https:/ / perma.cc/N89W-AL8R (accessed on 12 April 2021).

22. FAA. Information for operators (InFO) 16009: Title 14 of the Code of Federal Regulations (14 CFR) Part 121, § 121.703 Service Difficulty Reports (SDR); Federal Aviation Administration, Flight Standards Service: Washington, DC, USA, 2016. Available online: https:/ / perma.cc/G4T4-PV86 (accessed on 9 April 2021).

23. FAA. Report to Congress on Public Law 112-95, FAA Modernization and Reform Act of 2012, Section 917: Research and Development of Equipment to Clean and Monitor the Engine and Auxiliary Power Unit Bleed Air Supplied on Pressurized Aircraft. Prepared for FAA's Quality, Integration and Executive Services in Response to FAA's Aviation Safety legislative Implementation Plan by FAA's Office of Accident Investigation \& Prevention. U.S. Federal Aviation Administration: Washington, DC, USA, 2013. Available online: https:/ / perma.cc/F6SU-KVLG (accessed on 9 April 2021).

24. BFU. Study of Reported Occurrences in Conjunction with Cabin Air Quality in Transport Aircraft. Report No. BFU 803.1-14; Bundesstelle Für Flugunfalluntersuchung, German Federal Bureau of Aircraft Accident Investigation: Braunschweig, Germany, 2014. Available online: https:/ / perma.cc/XPR9-GE6E (accessed on 9 April 2021).

25. Airbus. A Clean APU Means Clean Cabin Air, Flight Airworthiness Support Technology (FAST). Airbus SAS 2013, 52, 4-9. Available online: https:/ / perma.cc/8PJ2-NVP8 (accessed on 9 April 2021).

26. AAIB. Report on the Serious Incident to Boeing 757-236, G-CPER on 7 September 2003; Air Accidents Investigation Branch, UK Department for Transport: Aldershot, UK, 2005. Available online: https://perma.cc/VJ66-3FLR (accessed on 12 April 2021).

27. Overfelt, R.A.; Jones, B.W.; Loo, S.M.; Haney, R.L.; Neer, A.J.; Andress, J.R.; Yang, X.; Zitova, A.; Prorok, B.C.; Fergus, J.W.; et al. Sensors and Prognostics to Mitigate Bleed Air Contamination Events; Report No. RITE-ACER-CoE-2012-05, Report Prepared for the Federal Aviation Administration; National Air Transportation Center of Excellence for Research in the Intermodal Transport Environment (RITE) Airliner Cabin Environment Research Program (ACER): Washington, DC, USA, 2012. Available online: https:/ / perma.cc/HCZ8-J687 (accessed on 12 April 2021).

28. O'Connor, M.; Stolzer, A. Hazard Identification: Voluntary Safety Reports of Potential Contaminated Bleed Air Events. NIOSH Western States Division and Embry-Riddle Aeronautical University. In Proceedings of the Aerospace Medical Association Annual Scientific Meeting, Las Vegas, NV, USA, 5-9 May 2019; Available online: https:/ / perma.cc/6RAL-BPUP (accessed on 14 April 2021).

29. U.S. Public Law 112-381, §917. Research and Development of Equipment to Clean and Monitor the Engine and APU Bleed Air Supplied on Pressurized Aircraft. 14 February 2012. Available online: https:/ / perma.cc/26SZ-557F (accessed on 12 April 2021).

30. EASA. Comment Response Document on Notice of Proposed Amendment 2009-10: Cabin Air Quality Onboard Large Aeroplanes; European Aviation Safety Agency: Cologne, Germany, 2011; Available online: https:/ / perma.cc/ZLS5-W2FM (accessed on 13 April 2021).

31. ATSB. An Analysis of Fumes and Smoke Events in Australian Aviation, 2008-2012; Aviation Research Report AR-2013-213; Australian Transport Safety Bureau: Canberra, Australia, 20 May 2014. Available online: https://perma.cc/Y2XQ-KSFL (accessed on 13 April 2021).

32. PCA. Chapter 6: Conclusions and recommendations. See Section 6.1.8; In Air Safety and Cabin Air Quality in the BAE 146 Aircraft; Senate Rural and Regional Affairs and Transport References Committee of the Parliament of the Commonwealth of Australia: Canberra, Australia, 2000; ISBN 0-642-71093-7. Available online: https:/ / perma.cc/TQ2E-VPG2 (accessed on 13 April 2021).

33. NRC. The Airliner Cabin Environment and the Health of Passengers and Crew; U.S. National Research Council; National Academy Press: Washington, DC, USA, 2002; 326p, ISBN 0-309-08289-7. Available online: https:/ / perma.cc/5L4Y-DJT7 (accessed on 14 April 2021).

34. FAA. Response to recommendation 1-Air quality and ventilation. In Report to the Administrator on the National Research Council Report, The Airliner Cabin Environment and the Health of Passengers and Crew; U.S. Federal Aviation Administration: Washington, DC, USA, 2002. Available online: https:// perma.cc/9QTP-CS82 (accessed on 14 April 2021). 
35. FAA. Information for Operators (InFO 10019): Smoke/Fumes in the Cabin/Cockpit of Transport Category Aircraft; U.S. Federal Aviation Administration Flight Standards Service: Washington, DC, USA, 2010. Available online: https://perma.cc/E6TB-Q8RE (accessed on 12 April 2021).

36. BTS. T-100 Data, All U.S. Carriers, All Airports (2002-2020). Bureau of Transportation Statistics, U.S. Department of Transportation, 2002-2011. Available online: https:/ / perma.cc/3RVC-SSGQ (accessed on 13 April 2021).

37. IATA. Global Safety Information Center STEADES Analysis: Smoke and Fumes (Smells in the Cabin and on the Flight Deck). Safety Trend Evaluation, Analysis, and Data Exchange System. Global Safety Information Center, International Air Transport Association: Montreal, Canada, 2013. Available online: https://perma.cc/GAK9-66HW (accessed on 14 April 2021).

38. Shehadi, M.; Jones, B.; Hosni, M. Characterization of the Frequency and Nature of Bleed Air Contamination Events in Commercial Aircraft. Indoor Air 2016, 26, 478-488. Available online: https:/ / doi.org/10.1111/ina.12211 (accessed on 12 April 2021). [CrossRef] [PubMed]

39. ASHRAE. Section 8.6 (Hydraulic Fluid) and Section 8.7 (Engine Oil). In Air Quality within Commercial Aircraft; ANSI/ASHRAE Standard 161-2018; American Society of Heating Refrigerating, and Air Conditioning Engineers: Atlanta, GA, USA, 2018; ISSN 1041-2336. Available online: https:/ / perma.cc/QDN6-EMJG (accessed on 13 April 2021).

40. AAIB. Bulletin No. 6/2009, G-BYAO (EW/C2006/10/08). In Air Accidents Investigation Branch; UK Department for Transport: Aldershot, UK, 2009. Available online: https:/ / perma.cc/Y5YQ-Q7MF (accessed on 13 April 2021).

41. U.S. Public Law 108-176, § 815(b)(5). Air Quality in Aircraft Cabins. 12 December 2003. Available online: https://perma.cc/DY4 P-UHB8 (accessed on 13 April 2021).

42. U.S. Public Law 112-381, §320(a)(4). Study of Air Quality in Aircraft Cabins. 14 February 2012. Available online: https: / / perma.cc/26SZ-557F (accessed on 13 April 2021).

43. FAA. Safety Alert for Operators (SAFO) 18003: Procedures for Addressing Odors, Smoke and/or Fumes in Flight; Federal Aviation Administration, Flight Standards Office: Washington, DC, USA, 2018. Available online: https:/ / perma.cc/GA2E-WWAJ (accessed on 13 April 2021).

44. U.S. Public Law 115-254, §326. Aircraft Air Quality. 5 October 2018. Available online: https:/ / perma.cc/H4UK-UPQ8 (accessed on 13 April 2021).

45. FAA. Information for Operators (InFO) 21002: Cabin Air Quality Educational Materials; Federal Aviation Administration, Flight Standards Office: Washington, DC, USA, 2021. Available online: https:/ / perma.cc/CS46-CW4E (accessed on 13 April 2021). 